\title{
Stem Cells and Tissue Engineering: Past, Present, and Future
}

\author{
JULIA M. POLAK AND ANNE E. BISHOP \\ Tissue Engineering \& Regenerative Medicine Centre, Imperial College, \\ Chelsea \& Westminster Campus, London SW10 9NH, UK
}

\begin{abstract}
Tissue engineering is an interdisciplinary field that brings together the principles of the life sciences and medicine with those of engineering. The increase in its development over the past decade has resulted from a variety of factors; advances in genomics and proteomics, the advent of new biomaterials as potential templates for tissue growth, improvements in bioreactor design, and increased understanding of healing processes. Possibly the greatest contribution has come from our increased knowledge and understanding of stem cell biology, which is paving the way for the generation of unlimited cells of specific phenotypes for incorporation into engineered tissue constructs. Thus, tissue engineering approaches for expanding and engrafting the differentiated progeny of embryonic, fetal, or adult stem cells have major potential for tissue repair and will make a major contribution to medicine in the 21 st century.
\end{abstract}

KEYWORDS: stem cells; tissue engineering; differentiation; bioactive materials

\section{PAST}

Tissue engineering has been broadly defined as the design and construction in the laboratory of living, functional components that can be used for the maintenance, regeneration, or replacement of malfunctioning tissues. Although it is widely assumed to be a relatively new field, the first report of tissue engineering was published in 1933 when tumor cells were implanted into a pig wrapped in a polymer membrane to protect them from immune attack. ${ }^{1}$ However, the modern era of tissue engineering could be said to have begun at the start of the 1980s with the development and clinical use of skin replacements. ${ }^{2,3}$ The field continues to expand and, although there have been some hold-ups on the industrial development side, including problems in devising cost-efficient scaleable processes, guaranteeing product viability, and

Address for correspondence: Julia M. Polak, Tissue Engineering \& Regenerative Medicine Centre, Imperial College, Chelsea \& Westminster Campus, Fulham Road, London SW10 9NH, UK. Voice: +44-208-237-2569; fax: +44-9746-5619.

e-mail: julia.polak@imperial.ac.uk

Ann. N.Y. Acad. Sci. 1068: 352-366 (2006). (C) 2006 New York Academy of Sciences. doi: 10.1196/annals.1346.001 
satisfying regulators, the basic research is rapidly evolving. Without doubt, a lot of the momentum that has driven the development of tissue engineering as a discipline in its own right has come from the quaternary of Vacanti brothers, Charles, Joseph, Martin, and Frank.

Tissue engineering is highly interdisciplinary and amalgamates the principles of the life sciences and medicine with those of engineering. The basic components of tissue engineering are cells, scaffolds, and signals. Tissue engineers have turned to virtually every cell type over the past two decades to try to define the best cell source for each particular tissue being constructed. A major advance has been the recognition of the huge advantages offered by stem cells; these include primarily their ability to self-renew, providing a theoretically inexhaustible supply, and to differentiate to any cell type when grown under the appropriate conditions.

This article provides a resumé of stem cell biology and tissue engineering, the current status quo, and we will also attempt to predict some of the key areas where stem cells are likely to be used successfully in future tissue engineering strategies.

\section{PRESENT}

\section{Tissue Engineering}

The challenge for tissue engineers is to optimize cell isolation, proliferation and, in the case of stem cells, differentiation and to design scaffolds and/or delivery systems that promote the coordinated growth of three-dimensional tissues. A widely used basic strategy has been to harvest cells from a patient, expand them in cell culture, and seed them onto a scaffold that provides a biomechanical environment that drives formation of the required tissue until the cells produce their own extracellular matrix. The tissue can be grown on a scaffold that will completely resorb as the new tissue grows, so that only the new tissue will be implanted; or a biocomposite on a permanent scaffold can be implanted. After implantation, the tissue engineered construct must then be able to survive, restore normal function, and integrate with the surrounding tissues.

\section{Cell Sources}

The single most important element to the success of tissue engineering is the ability to generate sufficient numbers of cells that maintain the appropriate phenotype and perform the required biological functions. For example, cells must produce extracellular matrix in the correct organization, secrete cytokines and other signaling molecules, and interact with neighboring cells/tissues. Immediately, this raises a number of potential problems, not least of which is obtaining appropriate cell numbers to promote repair. 


\section{Primary Cells}

Primary cells are mature cells specific to tissue type that are harvested from explant material removed by surgical procedure. An example is primary human osteoblasts that are harvested from the femoral heads removed during total hip replacement operations. Primary cells are the most desirable with regard to immunological compatibility but in general they are differentiated and post-mitotic. This can also be compounded by the tendency of some cell types to de-differentiate during ex vivo cultivation and express an inappropriate phenotype (e.g., articular chondrocytes in culture often produce fibrocartilage as opposed to hyaline cartilage). Although primary, especially autologous, cells are still used in tissue engineering, yields and proliferation rates tend to be low and for some phenotypes, e.g., spinal cord neurons, harvesting from a patient or donor is not an option. These limitations have stimulated studies to find and develop alternative cell sources for tissue engineering strategies and stem cells are already providing solutions to some of the problems encountered using primary cells released from explanted tissues.

\section{Stem Cells}

Stem cells can be defined as undifferentiated cells that can proliferate and have the capacity both to self-renew and to differentiate to one or more types of specialized cells. However, there has been some reconsideration of this definition recently in view of the observation of de-differentiation and transdifferentiation of certain mature cells. ${ }^{4-6}$ In view of this, it has been suggested that it should be made broader and applicable to a biological function that can be induced in a range of cell types, including differentiated cells, rather than a single entity. ${ }^{7}$ Stem cells can be isolated from embryos, fetuses, or from adult tissue, but the range of cell types to which they can differentiate varies. For tissue engineering, stem cells can provide a virtually inexhaustible cell source. Current research is focused on promoting stem cell differentiation to required lineages, purification of consequent cells, confirmation that there is no residual carcinogenic potential in the cell population, and implantation in a form that will replace, or augment the function of, diseased or injured tissues. An initial step is the selection of the most appropriate stem cell to form the required tissue.

Embryonic. Embryonic stem cells (ESC) are the most plastic cell source available to tissue engineers. ${ }^{8-10}$ They were first described more than two decades ago, when they were isolated from the inner cell mass of the developing murine blastocyst and grown in the laboratory. ${ }^{11,12} \mathrm{ESC}$ have since been shown to be totipotent, differentiating to all lineages, including the germ line and trophoblast. ${ }^{13-15}$ In vitro, murine ESC proliferate indefinitely in the 
undifferentiated state and retain the capacity to differentiate to all mature somatic phenotypes when they receive the appropriate signals. Maintenance of their undifferentiated state in culture depends on the presence of leukemia inhibitory factor (LIF) and serum or murine feeder layer cells. Study of the control of murine ESC self-renewal has recently shown that overexpression of the anti-apoptotic protein Bcl-2, acting in concert with LIF, removes the need for serum or feeders. ${ }^{16}$

The initial isolation of murine ESC lines gave developmental biologists a major tool as it provided a simple model system to study the processes of early embryonic development and cellular differentiation. However, it also paved the way for tissue engineering applications if similar totipotent cells could be extracted from human blastocysts. Human ESC were duly derived in $1998,{ }^{17,18}$ providing a tremendous boost for tissue engineering.

Human ESC show several distinct differences from murine ESC; they tend to proliferate more slowly and mostly form flat, rather than spherical, colonies. They are also generally easier to dissociate into single cells than their murine counterparts. ${ }^{19}$ Human ESC are unresponsive to LIF and most lines need to be grown on feeder layers in order to sustain self-renewal (FIG. 1). Much recent research has centered on the identification of the pathways controlling

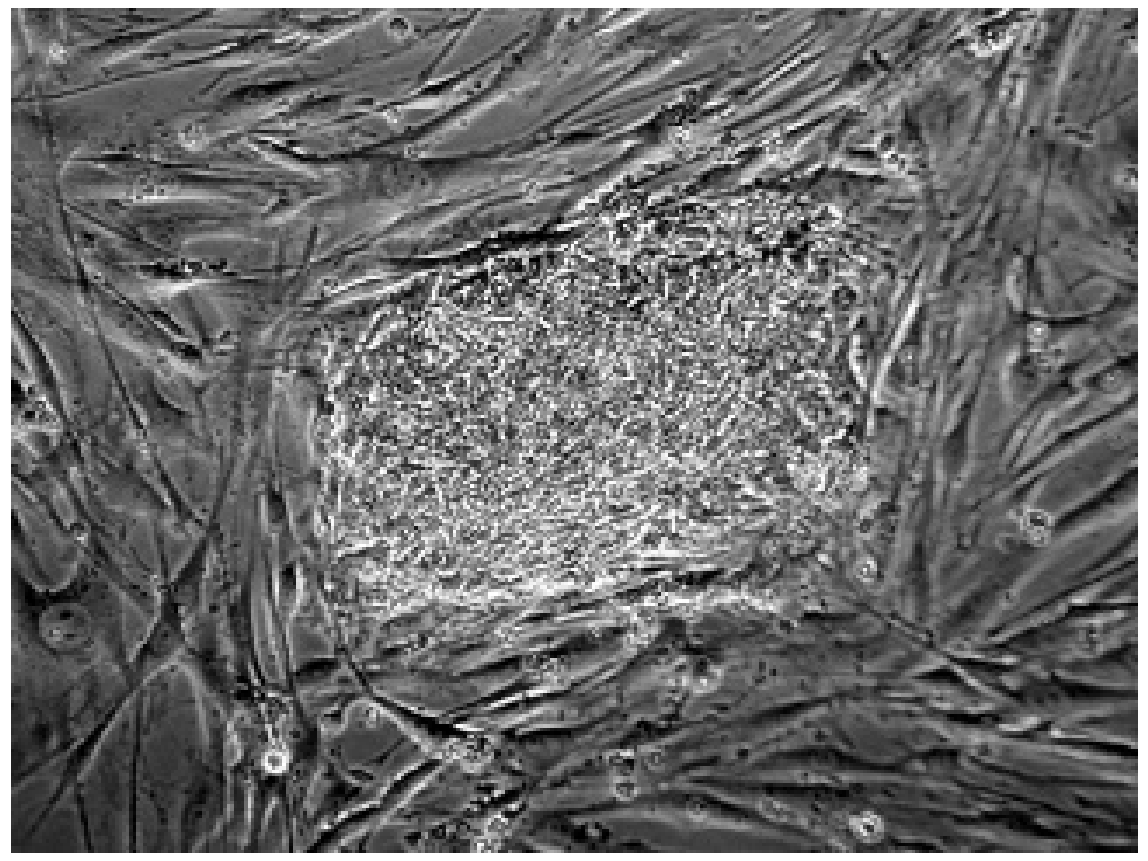

FIGURE 1. A colony of human ESC (H1) growing on a feeder layer of mitotically inactivated murine embryonic fibroblasts. (Inverted microscope image of living cells.) 
human ESC renewal. For tissue engineers, one of the main reasons for this has been the need to grow human ESC without any contamination by animal cells or proteins; a problem highlighted by a report in January 2005 that showed the expression of a nonhuman protein by human ESC lines grown on animal feeder layers. ${ }^{20}$ Various means have been tried, including addition of basic fibroblast growth factor to the culture medium, ${ }^{19,21}$ growth on matrigel or laminin in feeder cell-conditioned medium ${ }^{22}$ or in the presence of GSK-3specific inhibitors such as 6-bromoindirubin-3'-oxime (BIO), ${ }^{23}$ and growth on fibroblasts derived from human ESC. ${ }^{24,25}$ Although the adapted culture methods remove the need for animal feeder cells, none of the protocols is entirely free of animal products and so the problem remains.

Different cultures and religious groups have their own ethical stance on the use of human ESC. ${ }^{9}$ In the UK, human ESC lines can only be derived legally under licence from the Human Fertilization and Embryology Authority and the lines must be placed in the Medical Research Council's Stem Cell Bank. At present, the UK is the only country that allows cloning of human ESC and this is restricted to therapeutic nuclear transfer, to create autologous cells or to produce diseased cells for in vitro pathogenetic or drug discovery investigations, with reproductive cloning being illegal.

Fetal. The recent identification of human fetal mesenchymal stem cells (MSC) has raised the possibility of using autologous cells for in utero treatments. ${ }^{26}$ The MSC population extracted from fetal blood contains adherent cells that divide in culture for 20 to 40 passages and can differentiate into mesenchymal lineages including bone and cartilage, but also have the ability to form oligodendrocytes and hematopoietic cells. These cells, which can be found circulating only during the first trimester, are similar to hematopoietic populations in fetal liver and bone marrow and have been shown in a xenogeneic sheep model to engraft into multiple organs and undergo site-specific tissue differentiation.

Adult. An adult (or postnatal somatic) stem cell is an undifferentiated cell found among differentiated cells in a tissue or organ that can renew itself. There is an extensive repository of these stem cells located in various tissue niches throughout the body, including bone marrow, brain, liver, and skin as well as in the circulation (FIG. 2) ${ }^{27}$ Their main role is to maintain and repair the tissue in which they are found. Originally, these cells were considered to have only very limited differentiation potential but there have been many reports that they can show a considerable degree of plasticity although there is some debate about quite how much. ${ }^{28-32}$ In theory, therefore, these cells could be removed from a patient, incorporated into a tissue construct, and put back into the same individual when repair becomes necessary, thereby removing the need for immunosuppression. Clearly, adult-derived progenitor cells need to be investigated and their clinical usefulness established. However, as with 


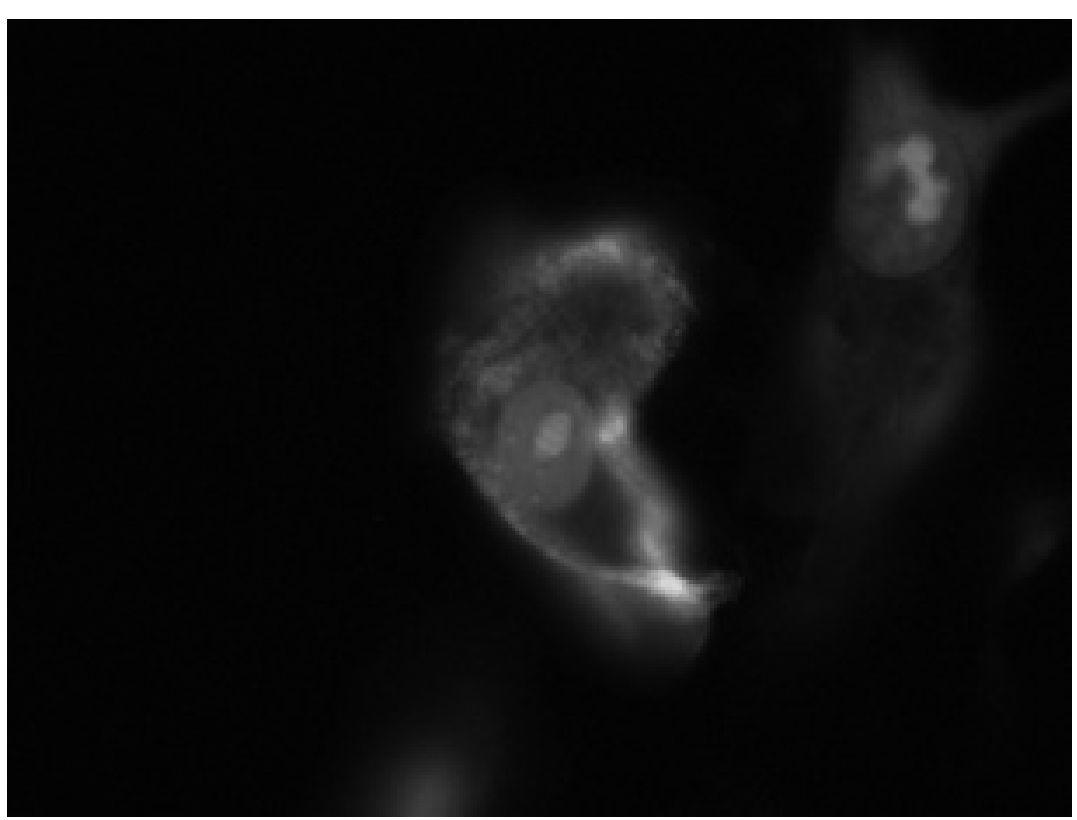

FIGURE 2. A single CD34-human cord blood stem cell fixed and immunostained for $\alpha$-feto-protein, a differentiation marker for endodermal cells. (Green: indirect immunofluorescence for $\alpha$-fetoprotein; red: propdium iodide as nuclear counterstain.)

primary mature cells, for some stem cell types, problems with accessibility, low frequency (e.g., there is roughly 1 stem cell per 100,000 bone marrow cells), restricted differentiation potential, and poor growth tends to limit their usefulness for tissue engineering. For a long time, adult stem cells have been considered to be a safer option for clinical applications than ESC because they have not been shown to form teratomas. However, new observations of the spontaneous transformation of human MSC during prolonged culture (4-5 months) argue for reassessment of the biosafety aspects of these cells. ${ }^{33}$ The situation is compounded for human MSC that have been transduced with the human telomerase reverse transcriptase gene (hTERT) in order to extend their life span and provide a large number of cells for therapeutic applications. ${ }^{34}$ These telomerized cells also undergo spontaneous genetic alteration leading to tumorigenicity in immunodeficient mice. ${ }^{35}$ Newly identified sources of stem cells include fat, ${ }^{36}$ placenta, ${ }^{37}$ and spleen. ${ }^{38}$ These sites can be an abundant source of stem cells; for example, a single gram of human adipose tissue has been reported to yield more than 70,000 pluripotent adipose-derived adult stem cells after 1 day in culture. ${ }^{36}$ 


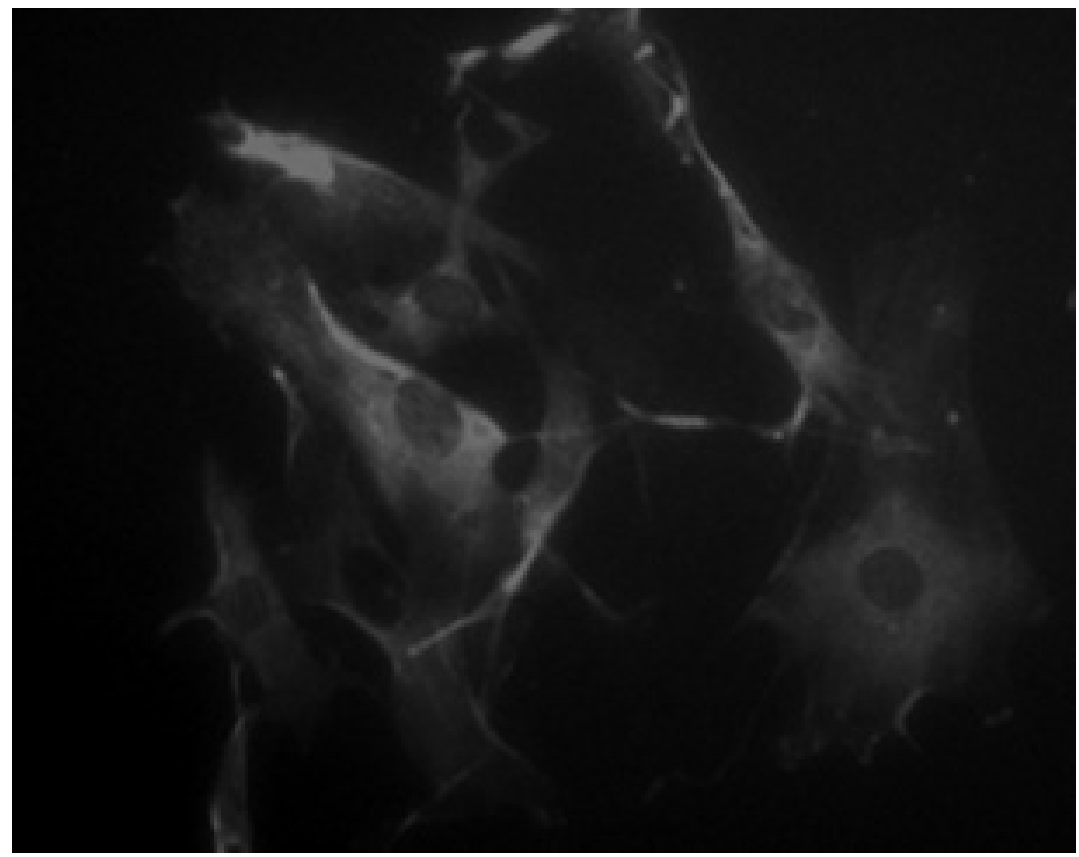

FIGURE 3. Type I pneumocytes, identified by their distinct morphology and immunoreactivity for aquaporin 5, differentiated from murine ESC by exposure to an extract of murine pneumocytes. (Red: indirect immunofluorescence for aquaporin 5.)

Directed differentiation of stem cells. Stem cells can be encouraged to differentiate to the required phenotype by manipulating the culture conditions under which they are maintained. In this way, it is possible to control or restrict the available differentiation pathways and to generate selectively cultures enriched with a particular phenotype. Such manipulations include stimulation of cells with particular cytokines, growth factors, amino acids, other proteins and active ions and co-culture with a relevant cell/tissue type (see Microenvironment). A new approach is to use cell extract-based re-programming, where permeabilized stem cells are exposed to extracts of the target phenotype (FIG. 3) ${ }^{39}$ Often, cell sorting techniques such as fluorescence-activated cell sorting (FACS) are used to purify the target cell type further. Using these approaches, virtually every cell type in the body has been derived from stem cells in the laboratory.

Stem cells, in particular ESC, are also amenable to genetic manipulation and have been instrumental in the creation of transgenic and gene knockout animals that provide the means for more detailed investigation of the genome and the specific functions of a particular gene. This genetic tractability also offers the potential to introduce genes to promote lineage-restricted differentiation and provides a basis for gene therapy to introduce therapeutic genes 
and potentially to modulate the immune response allowing implantation of "non-self" cells/tissues.

\section{SUPPORT MATERIALS}

The prime requirements for any scaffold in tissue engineering are biocompatibility, the capacity to sustain and/or promote the growth of the relevant cells/tissue, and provision of a template for tissue growth in three dimensions. Biological materials have frequently been used in tissue engineering; for example, the submucosa of the small bowel has been used in the engineering of blood vessels for 40 years. ${ }^{40,41}$ The tissues are decellularized and not only allogeneic but also xenogeneic sources have been used. Naturally occurring collagen has also been used in a variety of forms. There are obvious limitations associated with biological materials, including lack of consistency and structure malleability. The developments in materials science that have occurred in recent years, particularly in the generation of bioactive materials, have provided a major advance in tissue engineering. ${ }^{42-44}$ The new materials offer many advantages as they can be designed to meet specific spatial and strength requirements and their rate of degradation can be precisely controlled. Biocompatible, nonbiological materials fall into three classes: bioinert, resorbable, and bioactive. No material can be said to be totally inert when implanted but the group known as bioinert materials only provoke formation of scar tissue. The stainless steel used in artificial hips is an example of a widely used bioinert material. The resorbable materials eventually dissolve when implanted with the generation of harmless dissolution products. There is a wide range of such material already in clinical use such as the polymers (polyglycolic, PGA; polylactic acids, PLLA) used for suturing. These polymers have proved popular with tissue engineers as, in addition to already being used in the clinic, they are easy to shape and are tough with high tensile properties. Bioactive materials are those that stimulate a biological response from the body and are classified for bone tissue engineering as osteoconductive and osteoproductive. Osteoconductive materials (e.g., synthetic hydroxyapatite ceramics) bond to bone and stimulate growth at the edge of the graft while osteoproductive materials (e.g., bioactive glasses) stimulate the growth of new bone within the material. ${ }^{45}$

\section{MICROENVIRONMENT}

To maximize the chances of success, tissue engineers try to replicate as far as possible the natural microenvironment in which the cell/tissue would normally grow and function within the body. This comprises a range physical and chemical factors, broadly divided into physical (insoluble macromolecules, e.g., collagen), chemical (soluble macromolecules, e.g., cytokines), and cellcell interactions (proteins on adjacent cells). ${ }^{46}$ Thus, tissue engineers have 
provided extracellular matrix and soluble proteins to cells in constructs and, for load-bearing musculoskeletal tissues, mechanical stimulation may also be required. This approach is being refined by investigation of the specific cues cells receive in their local tissue milieu so that the crucial cells can be created in the tissue construct. ${ }^{47}$ For stem cells, co-culture with mature cells or tissues is also being used increasingly as a means to drive their differentiation toward required lineages. ${ }^{48-54}$

Among the latest developments in this area is the use of synthetic biomaterials to create microenvironments that mimic natural extracellular matrix, with the particular aim of directing stem cell differentiation and morphogenesis of the target tissue. ${ }^{46,55}$ This approach has been employed, for example, to construct a scaffold that enhances differentiation of neural stem cells while inhibiting the development of glial cells. ${ }^{56}$

\section{STEM CELL APPLICATIONS IN TISSUE ENGINEERING}

In aiming to get engineered tissues into the clinic, there is a variety of considerations in addition to identifying appropriate cell sources. Key among these are:

- Complex tissues: The final construct for implantation needs to replicate the architecture and complex cellular interdependence found in the corresponding normal tissue. Most current constructs involve only one or two cell types grown and their clinical viability is, therefore, limited.

- Vascularization: Rapid angiogenic stimulus is needed on implantation to ensure maintenance of the nutrient supply to the tissue construct as it integrates in situ.

- Interface stability: The host tissue-graft interface must permit/promote integration of the construct with the native tissue.

- Function: It must be possible to demonstrate that constructs will have the required level of normal activity in vivo.

- Storage: The viability of cell-based products needs to be maintained during storage and transport.

- Sterility: Sterility must be maintained during the production of each construct until implantation is complete. GMP compliance is essential.

- Cost: The manufacturing costs have limited the translation of many tissue engineering strategies to clinical applications. The background technology in tissue engineering continues to grow but there remains an urgent need to develop cost-efficient, scaleable processes, and rapid quality control tools.

At present, four main therapeutic approaches using stem cells have been defined: direct administration of adult stem cells, regeneration mediated by stimulation of endogenous stem cells, implantation of differentiated stem cells, 
and tissue engineering. Thus, stem cells are being used in the clinic, but most applications are based on the application of adult or fetal stem cells and involve cell delivery rather than tissue engineering per se. However, broader tissue engineering strategies, including those using ESC are being developed and tested. For example, engineered skin has been used for some time to treat burns and ulcers and most techniques expand basal keratinocytes, comprising stem, transient amplifying and committed cells, and fibroblasts from biopsies and grow them on structural or matrix proteins or on a polymer scaffold. ${ }^{57}$ For the skeleton, interoperative orthopedic procedures using adult stem cells are being developed, particularly for the treatment of patients with nonunion fractures. In these procedures adult osteogenic precursor cells, harvested from bone marrow, are grown on a scaffold and have the advantage over adult cells of laying down new extracellular matrix without the need for removal of old matrix, as happens with adult bone autografts. ${ }^{58,59}$ The first clinical application of bone engineered from stem cells was the successful grafting of the distal phalanx of the thumb comprising osteogenic cells from the distal radius periosteum. ${ }^{60}$ The recent demonstration that human ESC can be encouraged to form osteoblasts in vitro and in vivo provides a source for bone tissue engineering as well as a model system for studying bone formation. ${ }^{61}$ The fact that cartilage has no blood supply means that it has relatively little capacity for repair, although a progenitor cell population has recently been demonstrated within the surface of articular cartilage. ${ }^{62}$ Until now, tissue engineering of cartilage has been based mainly on the harvesting and expansion in vitro of autologous chondrocytes from articular surfaces on resorbable scaffolds, such as PGA. ${ }^{63-65}$ Human $\mathrm{MSC}^{66}$ and $\mathrm{ESC}^{67}$ yield chondrocytes in vitro and recent work growing rat MSC on a polyethylene glycol-based hydrogel has shown the formation of an entire chondryle, with chondral and osseous components, which suggests the potential of engineering total joints for replacement. ${ }^{68}$

Promising results are being obtained for the cardiovascular system. In the clinic, there has been success in the treatment of myocardial infarct by stem cell delivery using autologous bone marrow, although the clinical trials at present are mostly small and without satisfactory controls. ${ }^{69}$ ESC differentiated to cardiomyocytes were first tested as a means to repair the heart in an animal model in $1996 .{ }^{70}$ Although sufficient cardiomyocytes were generated, they did not become fully incorporated into the cardiac muscle in situ. More recently, implantation of undifferentiated murine ESC contained in a liquid matrix (Matrigel) into infarcted heart significantly improved contractility. ${ }^{71}$ Human ESC have been differentiated into endothelial cells that were isolated with antibodies to platelet endothelial cell adhesion molecule- $1 .{ }^{72}$ When cultured in matrigel in vitro, the cells formed tube-like structures and, when implanted into severe combined immune-deficient (SCID) mice on biodegradable polymer scaffolds, the cells appeared to form microvessels containing mouse blood cells. Tissue constructs, except for cartilage, need a microvascular network and attempts have been made to encourage vasculogenesis on scaffolds, for example, by 
seeding with endothelial progenitor cells (EPC) isolated from human cord blood. ${ }^{73}$ Interestingly, the EPC maintained their phenotype on PGA-PLLA scaffolds but only formed distinct capillary-like structures when they were seeded in combination with smooth muscle cells. ${ }^{74}$

\section{FUTURE}

The major medical challenges of the 21 st century are likely to be of a very different variety from those of today. Whereas fighting infectious disease has long been a preoccupation of medicine, in the future, dealing with the consequences of a predominantly aging population is likely to take priority. There is much to do if the full promise of stem cells and tissue engineering is to be realized. Our understanding of stem cell biology continues to increase but we must be able to not only control but also optimize the differentiation of stem cells. This includes determination of the signals that trigger differentiation, including chemical stimuli, matrix/substrate-associated cues, and the role of physical factors, with the latter being particularly unexplored.

Beyond the science, as stem cell biology is translated into clinical application, there are other issues and challenges that will need to be faced. The use of ESC remains contentious for some governments and religious groups and this position is unlikely to alter in the short term. However, governments change and, once clear clinical benefits are demonstrated, some current, opposing stances may become reconciled to the use of ESC. A pragmatic issue is the move from small-scale laboratory experiments to large-scale production of cells in GMP facilities. Clearly, innovative bioreactor technology will be needed. Standardization of the type and level of process quality controls will also be required to meet the conditions of the appropriate regulatory bodies.

If any kind of off-the-shelf availability of tissue and organs is to be achieved for a particular clinical application, then allogeneic cells will need to be employed. This raises the issue of the immunogencity of the cells. Everything that we now know suggests that a differentiated cell, one derived from a stem cell, will exhibit the normal immunogenic characteristics of that particular type of differentiated cell. If immune acceptance is an issue, there will then need to be a strategy for overcoming this. One means could be tissue typing, as is currently done for donor organs; and a recent publication suggests that as few as 150 ESC lines deposited in a bank may be sufficient to allow a satisfactory rate of matching. ${ }^{75}$ A possibility is therapeutic nuclear transfer and licences have been granted in the UK by the Human Embryology and Fertilization Authority for the cloning of human stem cells in order to make them immunocompatible.

In closing, finding the most effective ways of using stem cells, from adult, fetal, and embryonic sources, and triggering their differentiation in a controlled manner will provide cell banks for the in vitro growth of tissue and for cell 
replacement therapy. Developing these concepts from bench to bedside will be crucial in meeting healthcare needs in the new century.

\section{REFERENCES}

1. BisCeglie, V. 1933. Uber die antineoplastische immunitat; heterologe Einpflanzung von Tumoren in Huhner-embryonen. Ztschr. Krebsforsch 40: 122-140.

2. Bell, E., P. Ehrlich, D.J. Buttle, et al. 1981. Living tissue formed in vitro and accepted as skin-equivalent of full thickness. Science 221: 1052-1054.

3. BuRKe, J.F., I.V. YANNAS, W.C. QuimBY, et al. 1981. Successful use of a physiologically acceptable artificial skin in the treatment of extensive burn injury. Ann. Surg. 194: 413-448.

4. Bjornson, C.B., R.L. Rietze, B.A. Reynolds, et al. 1999. Turning brain into blood: a haematopoietic fate adopted by adult neural stem cells in vivo. Science 283: 534-537.

5. Mezey, E., K.J. ChandRoss, G. Harta, et al. 2000. Turning blood into brain: cells bearing neuronal antigens generated in vivo from bone marrow. Science 290: $1779-1782$.

6. Toma, J., M. AkHarvan, K.J.L. Fernandes, et al. 2001. Isolation of multipotent adult stem cells from the dermis of mammalian skin. Nat. Cell Biol. 3: 778784.

7. Blau, H.M., T.R. BRazelton \& J.M. Weimann. 2001. The evolving concept of stem cells: entity or function? Cell 105: 829-841.

8. RipPon, H.J. \& A.E. Bishop. 2004. Embryonic stem cells. Cell Prolif. 37: 23-34.

9. Mummery, C. 2004. Stem cell research: immortality or a healthy old age? Eur. J. Endocrinol. 151: U7-U12.

10. Wobus, A.M. \& K.R. BoHeLER. 2005. Embryonic stem cells: prospects for developmental biology and cell therapy. Physiol. Rev. 85: 635-678.

11. Evans, M.J. \& M.H. KaUfMAN. 1981. Establishment in culture of pluripotential cells from mouse embryos. Nature 292: 154-156.

12. MARTIN, G.R. 1981. Isolation of a pluripotent cell line from early mouse embryos cultured in medium conditioned by teratocarcinoma stem cells. Proc. Natl. Acad. Sci. USA 78: 7634-7638.

13. NAGY, A., E. GocZA, E.M. Diaz, et al. 1990. Embryonic stem cells alone are able to support fetal development in the mouse. Development 110: 815-821.

14. Bradley, A., M. Evans, M.H. Kaufman, et al. 1984. Formation of germ-line chimaeras from embryo-derived teratocarcinoma cells lines. Nature 309: $255-$ 256.

15. Xu, R.H., X. ChEN, D.S. LI, et al. 2002. BMP4 initiates human embryonic stem cells differentiation to trophoblast. Nat. Biotechnol. 20: 1261-1264.

16. Yamane, T., S.J. Dylla, M. Muijtjens, et al. 2005. Enforced Bcl-2 expression overrides serum and feeder cell requirements for mouse embryonic stem cell self-renewal. Proc. Natl. Acad. Sci. USA 102: 3312-3317.

17. Thomson, J.A., J. Itskovitz-Eldor, S.S. Shapiro, et al. 1998. Embryonic stem cell lines derived from human blastocysts. Science 282: 1145-1147.

18. Reubinoff, B.E., M.F. Pera, C.Y. Fong, et al. 2000. Embryonic stem cell lines from human blastocysts: somatic differentiation in vitro. Nat. Biotechnol. 18: 399-404. 
19. Laslett, A.L., A.A. FilipczyK \& M.F. Pera. 2003. Characterization and culture of human embryonic stem cells. Trends Cardiovasc. Med. 13: 295-301.

20. Martin, M.J., A. Muotri, F. Gage, et al. 2005. Human embryonic stem cells express an immunogenic nonhuman sialic acid. Nat. Med. 11: 228-232.

21. XU, R.H., R.M. PECK, D.S. LI, et al. 2005. Basic FGF and suppression of BMP signaling sustain undifferentiated proliferation of human ES cells. Nat. Methods 2: $185-190$.

22. Xu, C., M.S. Inokuma, J. Denham, et al. 2001. Feeder-free growth of undifferentiated human embryonic stem cells. Nat. Biotechnol. 19: 971-974.

23. Sato, N., L. Meijer, L. Skaltsounis, et al. 2004. Maintenance of pluripotency in human and mouse embryonic stem cells through activation of Wnt signaling by a pharmacological GSK-3-specific inhibitor. Nat. Med. 10: 55-63.

24. Xu, C., J. JiAng, V. SotTILE, et al. 2004. Immortalized fibroblast-like cells derived from human embryonic stem cells support undifferentiated cell growth. Stem Cells 22: 972-980.

25. Stojkovic, P., M. Lako, R. Stewart, et al. 2005. An autogeneic feeder cell system that efficiently supports growth of undifferentiated human embryonic stem cells. Stem Cells 23: 306-314.

26. Campagnol, C., I.A. Roberts, S. Kumar, et al. 2001. Identification of mesenchymal stem/progenitor cells in human first-trimester fetal blood, liver, and bone marrow. Blood 98: 2396-2402.

27. Presnell, S.C., B. Petersen \& M. Heidaran. 2002. Stem cells in adult tissues. Cell \& Dev. Biol. 13: 369-376.

28. Hawley, R.G. \& D.A. SobIESKI. 2002. Somatic stem cell plasticity: to be or not to be. Stem Cells 20: 195-197.

29. Holden, C. \& G. Vogel. 2002. Stem cells. Plasticity: time for a reappraisal? Science 296: 2126-2129.

30. Verfaillie, C.M., M.F. Pera \& P.M. LandsdorP. 2002. Stem cells: hype and reality. Hematology (Am. Soc. Hematol. Edu. Program) 2002: 369-391.

31. Poulsom, R., M.R. Alison, S.J. Forbes, et al. 2002. Adult stem cell plasticity. J. Pathol. 197: 441-456.

32. RafF, M. 2003. Adult stem cell plasticity: fact or artefact. Annu. Rev. Cell Dev. Biol. 19: 1-22.

33. Rubio, D., J. Garcia-Castro, M.C. Martin, et al. 2005. Spontaneous human adult stem cell transformation. Cancer Res. 65: 3035-3039.

34. Simonsen, J.L., C.RosadA, N.Serakinci, et al. 2002. Telomerase expression extends the proliferative life-span and maintains the osteogenic potential of human bone marrow stromal cells. Nat. Biotech. 20: 592-596.

35. Burns, J.S., B.M. ABdallah, P. GuldBerg, et al. 2005. Tumorigenic heterogeneity in cancer stem cells evolved from long-term cultures of telomerase-immortalized human mesenchymal stem cells. Cancer Res. 65: 3126-3135.

36. Wickham, M.Q., G.R. ERickson, J.M. Gimble, et al. 2003. Multipotent human adult stem cells derived from infrapatellar fat pad of the knee. Clin. Orthop. 412: 196-212.

37. Yen, B.L., H.I. HuAng, C.C. ChIEN, et al. 2005. Isolation of multipotent cells from human term placenta. Stem Cells 23: 3-9.

38. Kodama, S., M. Davis \& D.L. FAustMan. 2005. Diabetes and stem cell researchers turn to the lowly spleen. Sci. Aging Knowledge Environ. 2005: pe2.

39. QIN, M.D., G.P. TAI, P. Collas, et al. 2005. Cell extract-derived differentiation of embryonic stem cells. Stem Cells 23: 712-718. 
40. Matsumoto, T., R.H. Holmes, C.O. Burdick, et al. 1965. The fate of the inverted segment of small bowel used for the replacement of major veins. Surgery 60: 739-743.

41. Jernigan, T.W., M.A. Croce, C. Cagiannos, et al. 2004. Small intestinal submucosa for vascular reconstruction in the presence of gastrointestinal contamination. Ann. Surg. 239: 733-738.

42. Hench, L.L. \& J.M. PolaK. 2002. Third-generation biomedical materials. Science 295: $1014-1017$.

43. LANGer, R. \& D.A. TirRell. 2004. Designing materials for biology and medicine. Nature 428: 487-492.

44. Lutolf, M.P. \& J.A. HubBell. 2005. Synthetic biomaterials as instructive extracellular microenvironments for morphogenesis in tissue engineering. Nat. Biotechnol. 23: 47-55.

45. Jones, J.R. \& L.L. Hench. 2003. Regeneration of trabecular bone using porous ceramics. Curr. Opin. Solid State Mat. Sci. 7: 301-307.

46. KLeinman, H.K., D. Philip \& M.P. HofFman. 2003. Role of the extracellular matrix in morphogenesis. Curr. Opin. Biotechnol. 14: 526-532.

47. REDDI, A.H. 2000. Morphogenesis and tissue engineering of bone and cartilage: inductive signals, stem cells, and biomimetic biomaterials. Tissue Eng. 6: 351359.

48. Buttery, L.D.K., S. Bourne, J.D. Xynos, et al. 2001. Differentiation of osteoblasts and in vitro bone formation from murine embryonic stem cells. Tissue Eng. 7: 89-94.

49. Mummery, C., D. WARD, C.E. VAn DEN Brink, et al. 2002. Cardiomyocyte differentiation of murine and human embryonic stem cells. J. Anat. 200: 233-242.

50. Alexanian, A.R. \& M. Sieber-Blum. 2003. Differentiating adult hippocampal stem cells into neural crest phenotypes. Neuroscience 118: 1-5.

51. FAIR, J.H., B.A. CAIRNS, M. LAPAGLIA, et al. 2003. Induction of hepatic differentiation in embryonic stem cells by co-culture with embryonic cardiac mesoderm. Surgery 134: 189-196.

52. Ball, S.G., A.C. Shuttleworth \& C.M. Kielty. 2004. Direct cell contact influences bone marrow mesenchymal stem cell fate. Int. J. Biochem. Cell Biol. 36: 714-727.

53. Hwang, J.H., S.H. YuK, J.H. LeE, et al. 2004. Differentiation of stem cells isolated from rat smooth muscle. Mol. Cells 17: 57-61.

54. Van Vranken, B.E., H.M. Romanska, J.M. Polak, et al. 2005. Co-culture of embryonic stem cells with pulmonary mesenchyme: a microenvironment that promotes differentiation of pulmonary epithelium. Tissue Eng. 11: 1177-1187.

55. ZHANG, S. 2003. Fabrication of novel biomaterials through molecular selfassembly. Nat. Biotechnol. 21: 1171-1178.

56. Silva, G.A., C. Czeisler, K.L. NieCe, et al. 2004. Selective differentiation of neural progenitor cells by high epitope-density nanofibers. Science 303: $1352-$ 1355.

57. Margulis, A., W. Zhang \& J.A. Garlick. 2005. In vitro fabrication of engineered human skin. Methods Mol. Biol. 289: 61-70.

58. Muschler, G. \& R.J. Midura. 2002. Connective tissue progenitors: practical concepts for clinical applications. Clin. Orthop. 395: 66-80.

59. Muschler, G.F., H. Nitto \& Y. Matsukura. 2003. Spine fusion using cell matrix composites enriched in bone marrow-derived cells. Clin. Orthop. 407: 102118. 
60. Vacanti, C.A., L.J. Bonassar, M.P. VaCAnTI, et al. 2001. Replacement of an avulsed phalanx with tissue-engineered bone. N. Engl. J. Med. 344: 1511-1514.

61. Bielby, R.C., A.R. BOCCACCINI, L.D.K. ButTERY, et al. 2004. In vitro differentiation and in vivo mineralization of osteogenic cells derived from human embryonic stem cells. Tissue Eng. 10: 1518-1525.

62. Dowthwaite, G.P., J.C. Bishop, S.N. Redman, et al. 2004. The surface of articular cartilage contains a progenitor cell population. J. Cell Sci. 117: 889-897.

63. VACANTI, C.A., L.G. Cima \& D. RATOWSKI. 1992. Tissue-engineered growth of new cartilage in the shape of a human ear using synthetic polymers seeded with chondrocytes. Mat. Res. Sec. Symp. Proc. 252: 367-373.

64. Puelacker, W.C., J. Wisser, C.A. VaCanti, et al. 1994. Temperomandibular joint disc replacement made by tissue-engineered growth of cartilage. J. Oral Maxillofac. Surg. 52: 1172-1178.

65. Ibarra, C., C. JanetTA, C.A. Vacanti, et al. 1997. Tissue-engineered meniscus transplantation. Transplant. Proc. 29: 986-988.

66. Pittenger, M.F., A.M. MackAy, S.C. BeCK, et al. 1999. Multilineage potential of human adult mesenchymal stem cells. Science 284: 143-147.

67. VAts, A., R. BielBy, N. Tolley, et al. 2006. Chondrogenic differentiation of human embryonic stem cells: the effect of the micro-environment. Stem Cells Tiss. Eng. In press.

68. AlhadlaQ, A. \& J.J. MaO. 2005. Tissue-engineered osteochondral constructs in the shape of an articular condyle. J. Bone Joint Surg. Am. 87: 936-944.

69. Wollert, K.C., G.P. Meyer, J. LotZ, et al. 2004. Intracoronary autologous bonemarrow cell transfer after myocardial infarction: the BOOST randomised controlled clinical trial. Lancet 364: 141-148.

70. Klug, M.G., M.H. SoonPAa, G.Y. KoH, et al. 1996. Genetically selected cardiomyocytes from differentiating embryonic stem cells form stable intracardiac grafts. J. Clin. Invest. 98: 216-224.

71. Kofidis, T., J.L. DE BRUIN, G. Hoyt, et al. 2004. Injectable bioartificial myocardial tissue for large-scale intramural cell transfer and functional recovery of injured heart muscle. J. Thorac. Cardiovasc. Surg. 128: 571-578.

72. LevenberG, S., J.S. Golub, M. Amit, et al. 2002. Endothelial cells derived from human embryonic stem cells. Proc. Natl. Acad. Sci. USA 99: 4391-4396.

73. Kaushal, S., G.E. Amiel, K.J. Guleserian, et al. 2001. Functional small-diameter neovessels created using endothelial progenitor cells expanded ex vivo. Nat. Med. 7: 1035-1040.

74. Wu, X., E. Rabkin-AikaWA, K.J. Guleserian, et al. 2004. Tissue-engineered microvessels on three-dimensional biodegradable scaffolds using human endothelial progenitor cells. Am. J. Physiol. Heart Circ. Physiol. 287: H480-H487.

75. TAYlor, C.J., E. M. Bolton, S. Pocock, et al. 2005. Banking on human embryonic stem cells: estimating the number of donor cell lines needed for HLA matching. Lancet 366: 2019-2025. 